\title{
Combination of the histone deacetylase inhibitor vorinostat with bevacizumab in patients with clear-cell renal cell carcinoma: a multicentre, single-arm phase I/II clinical trial
}

Roberto Pili ${ }^{\star}, 1$, Glenn Liu ${ }^{2}$, Sreenivasulu Chintala ${ }^{1}$, Hendrick Verheul ${ }^{3}$, Shabnam Rehman ${ }^{4}$, Kristopher Attwood ${ }^{4}$, Martin A Lodge ${ }^{5}$, Richard Wahl ${ }^{5}$, James I Martin ${ }^{6}$, Kiersten Marie Miles ${ }^{4}$, Silvia Paesante ${ }^{4}$, Remi Adelaiye ${ }^{1}$, Alejandro Godoy ${ }^{7}$, Serina King ${ }^{5}$, James Zwiebel ${ }^{8}$ and Michael A Carducci ${ }^{5}$

${ }^{1}$ Genitourinary Program, Indiana University-Simon Cancer Center, Indianapolis, IN, USA; ${ }^{2}$ University of Wisconsin Carbone Cancer Center, Wisconsin, WI, USA; ${ }^{3}$ Vrije Universiteit Amsterdam, De Boelelaan 1105, 1081 HV Amsterdam, The Netherlands; ${ }^{4}$ Roswell Park Cancer Institute, Buffalo, NY, USA; ${ }^{5} J o h n s$ Hopkins Kimmel Cancer Center, Baltimore, MD, USA; ${ }^{6}$ Peninsula General Hospital, Santiago, Chile; ${ }^{7}$ Pontificia Universidad Catolica de Chile, Santiago, Chile and ${ }^{8}$ National Cancer Institute-CTEP, Bethesda, MD, USA

Background: Class II histone deacetylase (HDAC) inhibitors induce hypoxia-inducible factor- 1 and $-2 \alpha$ degradation and have antitumour effects in combination with vascular endothelial growth factor (VEGF) inhibitors. In this study, we tested the safety and efficacy of the HDAC inhibitor vorinostat and the VEGF blocker bevacizumab in metastatic clear-cell renal cell carcinoma (ccRCC) patients previously treated with different drugs including sunitinib, sorafenib, axitinib, interleukin-2, interferon, and temsirolimus.

Methods: Patients with up to two prior regimens were eligible for treatment, consisting of vorinostat $200 \mathrm{mg}$ orally two times daily $\times 2$ weeks, and bevacizumab $15 \mathrm{mg} \mathrm{kg}^{-1}$ intravenously every 3 weeks. The primary end points were safety and tolerability, and the proportion of patients with 6 months of progression-free survival (PFS). Correlative studies included immunohistochemistry, FDG PET/CT scans, and serum analyses for chemokines and microRNAs.

Results: Thirty-six patients were enrolled, with 33 evaluable for toxicity and efficacy. Eighteen patients had 1 prior treatment, 13 patients had 2 prior treatments, and 2 patients were treatment naïve. Two patients experienced grade 4 thrombocytopenia and three patients had grade 3 thromboembolic events during the course of exposure. We observed six objective responses (18\%), including one complete response and five partial responses. The proportion of patients with PFS at 6 months was $48 \%$. The median PFS and overall survival were 5.7 months (confidence interval (Cl): 4.1-11.0) and 13.9 months (Cl: 9.8-20.7), respectively. Correlative studies showed that modulation of specific chemokines and microRNAs were associated with clinical benefit.

Conclusions: The combination of vorinostat with bevacizumab as described is relatively well tolerated. Response rate and median PFS suggest clinical activity for this combination strategy in previously treated ccRCC.

Targeted therapies against the vascular endothelial growth factor (VEGF) signalling pathway have provided significant clinical benefit for patients with clear-cell renal cell carcinoma (ccRCC)
(Heng et al, 2013; Mittal and Rini, 2013). The genetic and epigenetic silencing of the Von Hippel-Lindau gene and consequent stabilisation of the hypoxia-inducible factor- 1 and $-2 \alpha$ (HIF- $1 \alpha$ and

*Correspondence: Professor R Pili; E-mail: rpili@iu.edu

Received 9 November 2016; revised 4 January 2017; accepted 20 January 2017; published online 21 February 2017

(C) 2017 Cancer Research UK. All rights reserved 0007-0920/17 
HIF- $2 \alpha$ ) are associated with the distinctive sensitivity of ccRCC to VEGF signalling pathway inhibitors (Shen and Kaelin, 2013). However, acquired resistance to antiangiogenics remains a major hurdle. The progression-free survival (PFS) and overall survival (OS) of patients with metastatic ccRCC is limited in duration, and eventually disease progression occurs (Rini, 2011). Several potential mechanisms have been identified in preclinical models of drug resistance, including hypoxia-driven alternative factors generated by tumour cells, proangiogenic activity of stroma and immune cells, and epithelial-to-mesenchymal transition (Hammers et al, 2010; Huang et al, 2010).

Hypoxia-induced growth factors are potential targets for therapeutic intervention. By concomitant blockade of HIFs and VEGF, 'vertical' inhibition of this angiogenic axis may exert effective vascular targeting and an antitumour effect (Kaelin, 2004). Several strategies aimed to affect HIFs have been developed (Rapisarda et al, 2009; Kummar et al, 2011; Jeong et al, 2014). Histone deacetylase (HDAC) inhibitors have been reported to have pleiotropic antiangiogenesis activity, including inhibition of HIFs (Qian et al, 2006b; Ellis et al, 2009). Class II HDACs, HDAC4, and HDAC6, associate with HIFs and stabilise the protein (Qian et al, 2006a). In the presence of HDAC inhibition, HIFs undergo acetylation and degradation via a Von Hippel-Lindau-independent but proteosome-dependent mechanism. Consequently, preclinical evidence has demonstrated that the combination of HDAC and VEGF receptor tyrosine kinase inhibition may achieve a greater antiangiogenic and antitumour effect than either agent alone (Qian et al, 2004).

Bevacizumab is a humanised monoclonal antibody that neutralises VEGF with a long half-life of 17-21 days. Bevacizumab in combination with interferon- $\alpha$ has been approved for the treatment of advanced kidney cancer (Rini et al, 2008). As a single agent, this monoclonal antibody generally has shown a mild toxicity profile, making this drug suitable for combination therapies. In a subset of patients with metastatic renal cell carcinoma who were previously on VEGFR tyrosine kinase inhibitors, bevacizumab treatment as a single agent produced a median PFS of 4.4 months and a median OS of 19.4 months. The overall response rate (ORR) was $9.5 \%$, and $52 \%$ patients had stable disease. Furthermore, in patients previously treated with VEGF and mammalian target of rapamycin (mTOR) inhibitors, the median PFS was 4.4 months and OS was 13.2 months (Turnbull et al, 2013).

Vorinostat is a small-molecule inhibitor of HDAC that binds directly in the enzyme active site in the presence of a zinc ion (Marks, 2007). Vorinostat targets most human Class 1 (related to the yeast transcriptional regulator Rpd3) and Class 2 (similar to the yeast Hda1) enzymes and has been approved for the treatment of cutaneous T-cell lymphomas (Olsen et al, 2007).

Preclinical results provide evidence that a pan-HDAC inhibitor may exert its antiangiogenic activity by impairing critical pathways in both tumour and endothelial cell compartments (Figure 1). Combination therapies with agents that target endothelial cells to block angiogenesis and HDAC inhibitors to prevent tumour adaptation to the resulting hypoxia by downregulating angiogenesis-related gene expression represents a rational therapeutic strategy in ccRCC. In this study, we evaluated the safety and efficacy of combining the HDAC inhibitor vorinostat with the VEGF inhibitor bevacizumab in patients with previously treated ccRCC.

\section{MATERIALS AND METHODS}

Study design and objectives. This was a multi-institutional, phase I/II clinical trial conducted at the Sidney Kimmel Comprehensive

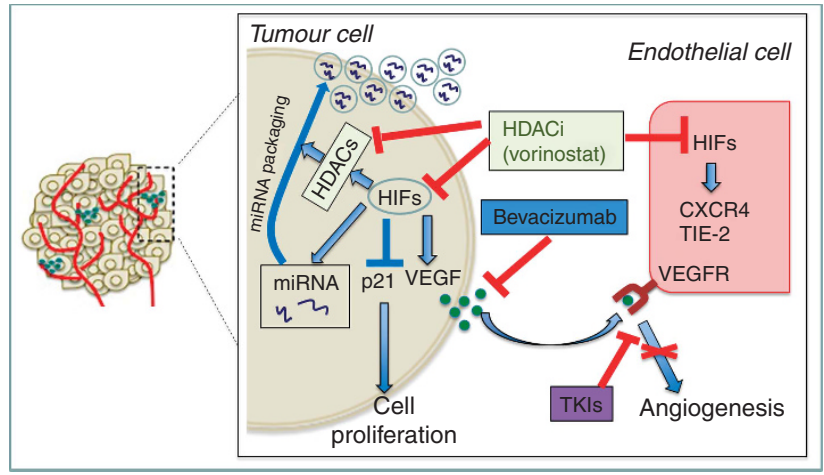

Figure 1. Proposed rationale for the combination of HDAC inhibitors and anti-VEGF therapies. Vorinostat inhibits HDACs and HIF and regulates the secretion of microRNA, growth factors, apoptotic, invasion and metastatic markers, and cytokines in renal cell carcinoma. Combination with VEGF inhibitors enhances the antitumour effects of HDAC inhibitors.

Cancer Center (SKCCC) at Johns Hopkins (Baltimore, MD, USA), the University of Wisconsin Carbone Cancer Center (Madison, WI, USA) and the Peninsula General Hospital (Salisbury, MD, USA). The phase 1 portion was conducted according to a deescalation design starting with full dose vorinostat and bevacizumab (200 mg per os twice a day for 14 days and bevacizumab $15 \mathrm{mg} \mathrm{kg}^{-1}$ intravenously, respectively, every 21 days). The primary end point of the phase I portion was to determine the safety and tolerability of vorinostat in combination with bevacizumab in patients with metastatic ccRCC. The phase II was conducted according to a Simons's two-stage, non-randomised, single-arm design. The primary efficacy end point of the phase II portion of the trial was the proportion of patients with 6 months of PFS receiving the combination therapy. For each patient, the time of progression was recorded.

Patient eligibility. Patients were required to have histologically confirmed metastatic or unresectable renal cell carcinoma with a clear-cell phenotype. Written informed consent, approved by the Institutional Review Board at each participating site, was obtained from all patients. During the completion of the phase I study, the eligibility criteria was changed to allow prior systemic treatments $(\leqslant 2)$ for metastatic disease, including immunotherapy, receptor tyrosine kinase inhibitor therapy, mTOR inhibitors, chemotherapy, and investigational therapy. Prior palliative radiation to metastatic lesion(s) was permitted, provided there was at least one measurable and/or evaluable lesion(s) that had not been irradiated and treatment completed $\geqslant 4$ weeks before registration. Patients were required to have measurable disease, defined as at least one lesion that could be accurately measured in at least one dimension as $>20 \mathrm{~mm}$ with conventional techniques or as $>10 \mathrm{~mm}$ with spiral CT scan (RECIST criteria; Therasse et al, 2000). ECOG performance status $\leqslant 1$ and life expectancy of $\geqslant 6$ months were required. Normal organ and marrow function was required, including leukocyte count $>3000 / \mathrm{mm}^{3}$, absolute neutrophil count $>1500 / \mathrm{mm}^{3}$, platelets $>100000 / \mathrm{mm}^{3}$, total bilirubin $<1.5 \times$ laboratory upper limit of normal, AST/ALT $\leqslant 2.5 \times$ laboratory upper limit of normal, creatinine $<1.5 \times$ laboratory upper limit of normal, or measured creatinine clearance of $>50 \mathrm{ml} \mathrm{min}^{-1}$ per $1.73 \mathrm{~m}^{2}, \mathrm{PT} / \mathrm{INR}<1.5$, and urine protein $<1+$. Patients on anticoagulants had to be without any active bleeding or pathological conditions that carried high risk of bleeding (e.g. tumour involving major vessels or known varices), and were required to have INR in the range of $2-3$ on a stable dose of warfarin or low-molecular-weight heparin. As HDAC inhibitors 
and bevacizumab are known to be teratogenic in animals, women of child-bearing potential were required to agree to use adequate contraception (hormonal or barrier method of birth control; abstinence) before study entry and for the duration of study participation. Patients with true papillary, sarcomatoid features without any clear-cell component, chromophobe, oncocytoma, collecting duct tumours, and transitional cell carcinoma were not eligible. Patients who were receiving other investigational agents or had been previously treated with bevacizumab, VEGF-Trap, or HDAC inhibitors, including valproic acid, were excluded. Patients with known CNS metastases or imaging abnormality indicative of CNS metastases were not included. Patients who had an active second malignancy other than non-melanoma skin cancers and had not completed their anticancer therapy or had $\geqslant 30 \%$ risk of relapse were not eligible. Patients with uncontrolled intercurrent illness including, but not limited to, ongoing or active infection, symptomatic congestive heart failure (New York Association Class II, III, or IV), angina pectoris requiring nitrate therapy, recent myocardial infarction (in past 6 months), cardiac arrhythmia, history of CVA within 6 months, hypertension (defined as blood pressure of $\geqslant 160 \mathrm{~mm} \mathrm{Hg}$ systolic and/or $\geqslant 90 \mathrm{~mm} \mathrm{Hg}$ diastolic on medications), history of peripheral vascular disease, or psychiatric illness/social situations that would limit compliance with study requirements, were ineligible. HIV-positive patients receiving combination antiretroviral therapy were ineligible because of the potential for pharmacokinetic interactions with vorinostat and increased risk of lethal infections. Patients who had a major surgical procedure, open biopsy, or significant traumatic injury within 28 days before day 1 of therapy or were anticipating the need for major surgical procedures during the course of the study or had core biopsy within first 7 days of therapy were excluded. Patients with a history of abdominal fistula, gastrointestinal perforation, or intra-abdominal abscess within 28 days before receiving treatment were also excluded. Other exclusion criteria included left ventricular ejection function $<45 \%$, evidence of bleeding diathesis or coagulopathy, presence of any serious or nonhealing wound, ulcer or bone fracture, and history of allergic reactions to compounds of similar chemical or biologic composition as vorinostat or hypersensitivity to Chinese hamster ovary cell products or other recombinant human antibodies.

Pre-treatment evaluation. Before treatment initiation patients had a complete history and physical examination, evaluation of ECOG performance status, CBC, coagulation profile, comprehensive metabolic profile, EKG, MUGA scan, urinalysis, and serum pregnancy test. The imaging for tumour characterisation and spread included CT, ultrasound, PET scan, bone scan, and MRI. The pathological confirmation needed to be, at least, in the form of either core needle biopsy or fine-needle aspirate. Baseline evaluations were conducted within 1 week before the start of therapy. Scans and $\mathrm{x}$-rays were performed within 4 weeks before the start of therapy and were repeated every 6 weeks.

Treatment. Treatment was administered in 3-week (21 days) cycles. In each cycle, vorinostat was administered orally using $100 \mathrm{mg}$ capsules preferably with food $(200 \mathrm{mg}$ twice daily from days 1 to 14), whereas bevacizumab (15 mg kg-1 in $100 \mathrm{ml}$ normal saline) was given as intravenous infusion on day 1 of each cycle. The choice of 14 days of vorinostat with 7 days off therapy was based on previous evidences that continuous dosing of HDAC inhibitors induces significant fatigue. The 21-day dosing of bevacizumab was chosen based on previous studies in colon cancer patients, suggesting that this drug can be dosed either every 2 or 3 weeks because of its long half-life. Patients were evaluated after every two-cycle period (6 weeks) for disease progression by CT scan, and for toxicity, treatment discontinuation, and need for alternative forms of treatment after each cycle. The treatment was continued until disease progression, intercurrent illness that prevented further administration of treatment, unacceptable adverse event(s), or patient decided to withdraw from the study. Patients were followed at 4 weeks after last dose of study drugs for toxicity evaluation in the clinic, and then every 3 months or until death, whichever occurred first. Patients removed from the study for unacceptable adverse events or continued to experience adverse events attributable to the study drug at the end of study visit were followed until resolution or stabilisation of the adverse events.

Dose modifications. The starting dose of vorinostat was $200 \mathrm{mg}$ orally twice a day (dose level 1) from days 1 to 14 . If dose-limited toxicity (DLT), defined as any grade 3 or 4 toxicity or any toxicity unresponsive to supportive care or for which treatment had been delayed for $>2$ weeks, occurred during the first cycle (first 21 days) at dose level 1, patient dose level was de-escalated to dose level 0 ( $100 \mathrm{mg}$ twice a day). The dose of bevacizumab was $15 \mathrm{mg} \mathrm{kg}^{-1}$ intravenously on day 1 , every 21 days. There was no dose reduction for bevacizumab. If DLT was attributed to bevacizumab, the patient had to come off study.

Toxicity and response evaluation. Toxicities were recorded as per CTCAE v3 and were summarised using descriptive statistics. In the phase II, the patient clinical responses were evaluated using the RECIST criteria. The primary efficacy end point of the phase II portion of the trial was the proportion of patients with 6 months of PFS defined as no evidence of either clinical or anatomic progression by imaging studies. For some of the correlative studies, patients were classified as Responders if they achieved an objective response, and Progressors if they had progressive disease as best response.

Enzyme-linked immunoabsorbent assay of VEGF. Secreted VEGF levels were determined in the serum of patient samples before and after treatment using the Quantikine ELISA human VEGF Immunoassay Kit (Minneapolis, MN, USA) as per the procedure described by the manufacturer (R\&D Systems, Minneapolis, MN, USA). Vascular endothelial growth factor levels were compared before and after the treatment. The blood samples were collected at baseline, $48-72 \mathrm{~h}$ after the first infusion of bevacizu$\mathrm{mab}$, right before the third infusion of bevacizumab (pre-C3), and at the end of treatment.

Immunohistochemical detection of HIFs. Immunohistochemical analysis of HIF- $1 \alpha$ and $-2 \alpha$, VEGF, and carbonic anhydrase-IX (CAIX) were performed as described previously (Chintala et al, 2010, 2012). A score system (0 vs + ) was applied based on the percentage of cells stained $(0<10 \% v s>10 \%)$. Respective isotypematched negative controls were used in place of primary antibodies. Percent positive cases were determined from the total evaluable tumours $(n=18)$.

Luminex $\times$ MAP technology for protein analysis. Multiplex Luminex Kit (EMD Millipore, Billerica, MA, USA) human circulating cancer biomarker panel 1 was used to determine serum levels of secreted growth factors (VEGF, FGF2, and HGF), apoptotic markers (sFAS-L and TRAIL), invasion and metastatic markers (SDF and OPN), and cytokines (IL-8) in patients before and after treatment according to the protocols specified by manufacturer.

Circulating microRNA analysis. MicroRNA was isolated from serum samples using the miRNeasy Mini Kit (Qiagen, Germantown, MD, USA) according to the protocols specified by manufacturer. Serum samples analysed for miRNAs were collected at baseline and pre-C3. Briefly, $50 \mu \mathrm{l}$ of serum sample was mixed with $190 \mu \mathrm{l}$ of QIAzole lysis reagent with carrier MS2 RNA, incubated for $5 \mathrm{~min}$, and $50 \mu \mathrm{l}$ of chloroform was added and further incubated for $2 \mathrm{~min}$. Contents were centrifuged at $12000 \mathrm{~g}$ for $15 \mathrm{~min}$ at $40{ }^{\circ} \mathrm{C}$ and the upper aqueous phase was transferred to a microcentrifuge tube. Ethanol was added to the aqueous phase, 
mixed well, and transferred to a RNeasy Mini spin column (Qiagen) on a QiaVac Manifold and washed with $500 \mu$ of RWT buffer, followed by three times RPE buffer. Spin column was transferred to collection tube centrifuge at $15000 \mathrm{~g}$ for $2 \mathrm{~min}$ at room temperature, transferred to new collection tube, and air dried for $1 \mathrm{~min}$. RNA was eluted by adding $50 \mu \mathrm{l}$ of RNase-free water on the membrane and centrifugation at $15000 \mathrm{~g}$ for $1 \mathrm{~min}$ at room temperature. Quantitative RT-PCR was performed to determine the expression of miRNA using the Exiqon serum/plasma Focus microRNA PCR panel with specific miRNA primers in triplicate using Roche Light Cycler 480 (Indianapolis, IN, USA) according to the protocol described by manufacturer (Exiqon, Woburn, MA, USA). MicroRNA Ready-to-use PCR, Human panel I + II, V4.M and 752 human microRNA, miRcurry LNA Universal RT microRNA PCR (Exiqon) were used for analysis. Normalisation of Exiqon miRNA panels were carried out according to the Exiqon Manual using the interplate calibrator. SYBR Green was used to acquire the signal and for quality control of each plate. GenEx Software (Exiqon) was used to normalise the plates and eliminate run-to-run variation when comparing multiple plates. Data were presented as individual triplicate runs and as averages of triplicates. Confirmation of microRNA 605 expression in patients samples of serum was done by quantitative RT-PCR using TaqMan Small RNA Assays kit (Applied Biosystems-ThermoFisher Scientifics, Carlsbad, CA, USA). MicroRNA 605 trascription kit was used to prepare the cDNA and PCR was performed using the TaqMan $2 \mathrm{X}$ Universal PCR Master Mix, with AmpErase UNG kit (Applied Biosystems-ThermoFisher Scientifics) according to the protocol described by manufacturer.

Statistical considerations. The proportion of patients with 6 months of PFS was calculated with exact $95 \%$ confidence intervals (CIs). Based on the original design to enroll treatment-naïve patients, the sample size of 36 patients treated at the recommended phase II doses gave an $85 \%$ power to distinguish a proportion of 0.6 from the null value of 0.4 , using Simon's two-stage design with a one-sided test of proportion and an $\alpha$-level of 0.1 . An interim analysis was performed after the first 26 patients were observed for 6 months with $\leqslant 14$ patients who progressed. The overall and progression free survival are summarised for the evaluable patients $(n=33)$ using standard Kaplan-Meier (KP) methods. The median survival times and 6-month survival rates were estimated based on the KP curve, with corresponding 95\% CIs obtained using the loglog method. All analysis were conducted in SAS v.9.3 (SAS, Cary, NC, USA). The survival time was calculated from the date of first treatment until the date of death or last follow-up. The PFS time was calculated from the date of the first treatment until the date of progression/death or last follow-up.

\section{RESULTS}

General. The clinical trial opened in March 2006 and the last patient was accrued on September 2009. Thirty-six patients were accrued, and 33 were evaluable for safety and efficacy. Eighteen patients had one prior treatment, 13 patients had 2 prior treatments, and 2 patients were treatment naïve. Prior treatments included sunitinib, sorafenib, axitinib, interleukin 2, interferon $\alpha$, and temsirolimus. The patient characteristics are summarised in Table 1.

Safety and tolerability. In the phase I portion, 8 patients were enrolled and no DLTs were observed. Vorinostat $200 \mathrm{mg}$ per os twice a day for 14 days and bevacizumab $15 \mathrm{mg} \mathrm{kg}^{-1}$ intavenously every 21 days were the recommended phase II doses. Two patients were taken off study during cycle 2, one due to unrelated stridor and another due to grade 4 thrombocytopenia. Two out of the remaining six patients received dose reductions primarily due to
Table 1. Patient characteristics

\begin{tabular}{|c|c|c|}
\hline Characteristics & No. & $\%$ \\
\hline \multicolumn{3}{|l|}{ Age (years) } \\
\hline $\begin{array}{l}\text { Median } \\
\text { Range }\end{array}$ & \multicolumn{2}{|c|}{$\begin{array}{c}62.7 \\
34-82\end{array}$} \\
\hline \multicolumn{3}{|l|}{ Sex } \\
\hline $\begin{array}{l}\text { Male } \\
\text { Female }\end{array}$ & $\begin{array}{c}30 \\
3\end{array}$ & $\begin{array}{c}91 \\
9\end{array}$ \\
\hline \multicolumn{3}{|l|}{ ECOG PS } \\
\hline $\begin{array}{l}0 \\
1\end{array}$ & $\begin{array}{l}11 \\
22\end{array}$ & $\begin{array}{l}33 \\
67\end{array}$ \\
\hline \multicolumn{3}{|l|}{ Tumour histology } \\
\hline $\begin{array}{l}\text { Clear cell } \\
\text { Mixed/clear-cell predominant } \\
\text { Mixed/papillary predominant } \\
\text { Prior nephrectomy } \\
\text { Prior radiotherapy }\end{array}$ & $\begin{array}{c}23 \\
8 \\
2 \\
31 \\
10\end{array}$ & $\begin{array}{c}70 \\
24 \\
6 \\
94 \\
30\end{array}$ \\
\hline \multicolumn{3}{|l|}{ Prior systemic therapy } \\
\hline $\begin{array}{l}\text { Sunitinib } \\
\text { Sorafenib } \\
\text { Cytokine therapy }\end{array}$ & $\begin{array}{c}28 \\
5 \\
10\end{array}$ & $\begin{array}{l}85 \\
15 \\
33\end{array}$ \\
\hline \multicolumn{3}{|c|}{ No. of prior systemic treatments } \\
\hline $\begin{array}{l}0 \\
1 \\
2\end{array}$ & $\begin{array}{c}2 \\
18 \\
13\end{array}$ & $\begin{array}{c}6 \\
54.5 \\
39.5\end{array}$ \\
\hline \multicolumn{3}{|l|}{ MSKCC risk groups } \\
\hline $\begin{array}{l}\text { Good } \\
\text { Intermediate } \\
\text { Poor }\end{array}$ & $\begin{array}{c}10 \\
20 \\
3\end{array}$ & $\begin{array}{l}30 \\
60 \\
10\end{array}$ \\
\hline
\end{tabular}

fatigue. Dose reductions during the phase I portion were after at least three cycles or more. One patient was ultimately taken off the study at cycle 8 because of grade 3 pulmonary embolism and hemothorax after starting warfarin treatment. During the phase II portion, fatigue (grade 1) was the most commonly occurring adverse effect $(61 \%)$, followed by nausea (48\%), pain $(48 \%)$, anorexia (45\%), diarrhoea (36\%), and elevated creatinine $(36 \%$; grade 1). Grade 3-4 toxicities (6\%) included thrombocytopenia, a thromboembolic event, and fatigue. The adverse effect profile is outlined in Table 2. Overall, 10 patients discontinued treatment due to toxicities, including two patients who had related SAEs (grade 4 thrombocytopenia and pulmonary embolism).

Clinical efficacy. The treatment effect of vorinostat and bevacizumab combination is depicted in Figure 2. The median PFS and overall OS were 5.7 months (CI: 4.1-11.0) and 12.9 months (CI: 9.8-20.7), respectively. The PFS and OS rates at 6 months were $48.6 \%$ and $83.8 \%$, respectively. The majority of patients had some tumour shrinkage. Among the patients with no clinical benefit, there were also the two treatment-naïve patients. We observed six objective responses (18\%), including one complete response (prior sunitinib treatment) and five partial responses. Nineteen patients (67\%) had stable disease (12-84 weeks), including two patients with confirmed objective response for more than 2 years.

Immunohistochemistry studies. To assess whether the HIF status was associated with response to the combination of vorinostat and bevacizumab, we analyzed the archived tissues from the original nephrectomy specimens when available (18 patients). Marker positivity was defined as $\geqslant 10 \%$ cellular staining. Immunohistochemical staining for HIF- $1 \alpha$ was positive in $33 \%$ (6 out of 18 specimens), whereas it was positive in 67\% (12 out of 18 specimens) for HIF- $2 \alpha$ and $72 \%$ (13 out of 18 specimens) for 
Table 2. Summary of adverse events (AEs)

\begin{tabular}{|c|c|c|c|c|}
\hline AE event & $\begin{array}{c}\leqslant \text { Grade } 2 \\
(\%)\end{array}$ & $\begin{array}{c}\text { Grade } 3 \\
(\%)\end{array}$ & $\begin{array}{c}\text { Grade } 4 \\
(\%)\end{array}$ & Total (\%) \\
\hline Fatigue & $17(52)$ & $3(9)$ & 0 & $20(61)$ \\
\hline Nausea & $16(48)$ & 0 & 0 & $16(48)$ \\
\hline Pain & $16(48)$ & 0 & 0 & $16(48)$ \\
\hline Anorexia & $14(42)$ & $1(3)$ & 0 & $14(45)$ \\
\hline Diarrhoea & $11(33)$ & $1(3)$ & 0 & $12(36)$ \\
\hline Creatinine & $12(36)$ & 0 & 0 & $12(36)$ \\
\hline Haemorrhage & $8(24)$ & $1(3)$ & 0 & $9(27)$ \\
\hline Hyperglycaemia & $8(24)$ & $1(3)$ & 0 & $9(27)$ \\
\hline Hyperkalaemia & $7(21)$ & $1(3)$ & 0 & $8(24)$ \\
\hline Vomiting & $8(24)$ & 0 & 0 & $8(24)$ \\
\hline Platelets & $5(15)$ & 0 & $2(6)$ & $7(21)$ \\
\hline Haemoglobin & $7(21)$ & 0 & 0 & $7(21)$ \\
\hline Weakness & $7(21)$ & 0 & 0 & $7(21)$ \\
\hline $\begin{array}{l}\text { Alkaline } \\
\text { phosphatase }\end{array}$ & $4(12)$ & $1(3)$ & 0 & $5(15)$ \\
\hline Dizziness & $4(12)$ & $1(3)$ & 0 & $5(15)$ \\
\hline Hypercalcaemia & $4(12)$ & $1(3)$ & 0 & $5(15)$ \\
\hline Dehydration & $5(15)$ & 0 & 0 & $5(15)$ \\
\hline Headache & $5(15)$ & 0 & 0 & $5(15)$ \\
\hline Abdominal pain & $3(9)$ & $1(3)$ & 0 & $4(12)$ \\
\hline DVT/PE & 0 & $3(9)$ & 0 & $3(9)$ \\
\hline Hypertension & $2(6)$ & $1(3)$ & 0 & $3(9)$ \\
\hline Albumin & $3(9)$ & 0 & 0 & $3(9)$ \\
\hline Neutropenia & $3(9)$ & 0 & 0 & $3(9)$ \\
\hline ALT & $1(3)$ & $1(3)$ & 0 & $2(6)$ \\
\hline Pneumonia & $1(3)$ & $1(3)$ & 0 & 2 (6) \\
\hline AST & $1(3)$ & $1(3)$ & 0 & $2(6)$ \\
\hline Bilirubin & $1(3)$ & $1(3)$ & 0 & $2(6)$ \\
\hline Confusion & $1(3)$ & $1(3)$ & 0 & $2(6)$ \\
\hline Hypocalcaemia & $1(3)$ & $1(3)$ & 0 & $2(6)$ \\
\hline $\begin{array}{l}\text { Dyspnoea on } \\
\text { exertion }\end{array}$ & $2(6)$ & 0 & 0 & $2(6)$ \\
\hline
\end{tabular}

Abbreviations: $A L T=$ alanine aminotransferase; $A S T=$ aspartate transaminase; DVT = deep vein thrombosis; $\mathrm{PE}=$ pulmonary embolism.

VEGF (Figure 3A). The positive staining for CAIX was 93\% (13 out of 14 specimens). No clear association with clinical response was observed.

Modulation of serum chemokines. To determine potential secreted biomarkers predictive of response, we evaluated serum levels of secreted growth factors (VEGF, FGF2, and HGF), invasion and metastatic markers (SDF and OPN), and cytokines (IL-8). While we observed a significant decrease in serum VEGF, not plasma VEGF, in all of the patients following treatment, there was no clear association between biological and clinical outcome (Figures 3B and C). Next, to analyse other chemokines and soluble markers, we grouped patients as Responders (those who achieved objective response by RECIST) and Progressors (those who had progressive disease as best response by RECIST). The data presented in Figure 4A show the downregulation of secreted FGF2, SDF, OPN, and IL-8 in the group of patients who achieved an objective response (three Responders), as compared with the patients who had progressive disease as best response (four Progressors). These results suggest the potential role of circulating chemokines as predictors of response in ccRCC patients.
Modulation of circulating miRNA. MiRNA deregulation in ccRCC has been reported (Khella et al, 2013). A recent study has shown a significant downregulation of miRNA 451 in ccRCC patient serum (Redova et al, 2012). Thus, in search of potential biomarkers predictive of response, we isolated miRNA from serum samples collected pre- and post-treatment and determined the expression of circulating microRNAs. As shown in Figure $4 \mathrm{~B}$, the baseline levels in the Responders group (three patients) showed differential expression of selected miRNA as compared with the Progressors group (four patients). We observed a downregulation of miR.20a, miR.142.3p, miR.154, miR.199a.5p and miR.let.7b and an upregulation of $m i R .99 a, m i R .605, m i R .485 .3 p, m i R .365$, and miR.451. To evaluate the effect of vorinostat and bevacizumab treatment on miRNA, we assessed the expression of these miRNAs in the Responders and Progressors groups, pre- and posttreatment. We observed a significant downregulation of $m i R .142 .3 p$, miR.154, and miR.199a.5p and a significant upregulation of $m i R .20 a$ and miR.let.7b with treatment in three patients classified as Responders (0.8-2.8 fold change). Interestingly, miR.20a and miR.let7.b, whose baseline expressions were downregulated in the Responders group, were significantly upregulated after treatment, suggesting a potential role in the observed responses. The expression of $m i R .605$, miR.485.3p, and $m i R .365$, which was upregulated in the Responders group at baseline, was significantly downregulated following treatment. Additionally, the expression of miR.451, which was found to be upregulated in the Responders group at baseline, decreased after treatment. In the Progressors group (four patients), the expression of these miRNAs was reversed as compared with the Responders group. We confirmed higher levels of miR.605 in Responders vs Progressors by Q-PCR (Figure 4C).

\section{DISCUSSION}

Progressive disease following anti-VEGF therapies remains a major hurdle in the treatment of ccRCC. This study was originally designed to test the combination of bevacizumab and vorinostat in treatment-naïve patients, but the concurrent approval of sunitinib and sorafenib led to a change in the design by allowing up to two prior therapies. The original 6-month PFS rate of 0.60 was not met, but the primary end point was originally set with the assumption that patients were going to be treated in the first-line setting. However, the median PFS of 5.7 months and an ORR of $18 \%$ suggest that the combination of vorinostat and bevacizumab has clinical activity in patients with TKI-resistant ccRCC. No significant adverse events were observed to suggest overlapping toxicities with bevacizumab and vorinostat. Biological activity is also suggested by the modulation of specific chemokines and microRNAs. These observations support the concept that further investigation of the role of HDAC inhibition in the context of VEGF blockade should be considered.

Continuous VEGF inhibition appears to be important in inducing prolonged clinical response in ccRCC patients. The approval of axitinib has confirmed retrospective studies, suggesting that sequencing of TKIs can still induce disease control despite progression following front-line therapies with anti-VEGF therapies (Rini et al, 2011). The role of VEGF ligand blockade by bevacizumab in the second- and third-line setting has not been clearly defined. A report showed that bevacizumab treatment induced an ORR of $9 \%$ and a PFS of 4.4 months in previously treated ccRCC patients (Turnbull et al, 2013). We cannot rule out the possibility that our result may have been due to the bevacizumab alone, although this seems unlikely based on the historical ORR and PFS data with this drug. Phase II studies with combination of bevacizumab with either everolimus or 
A
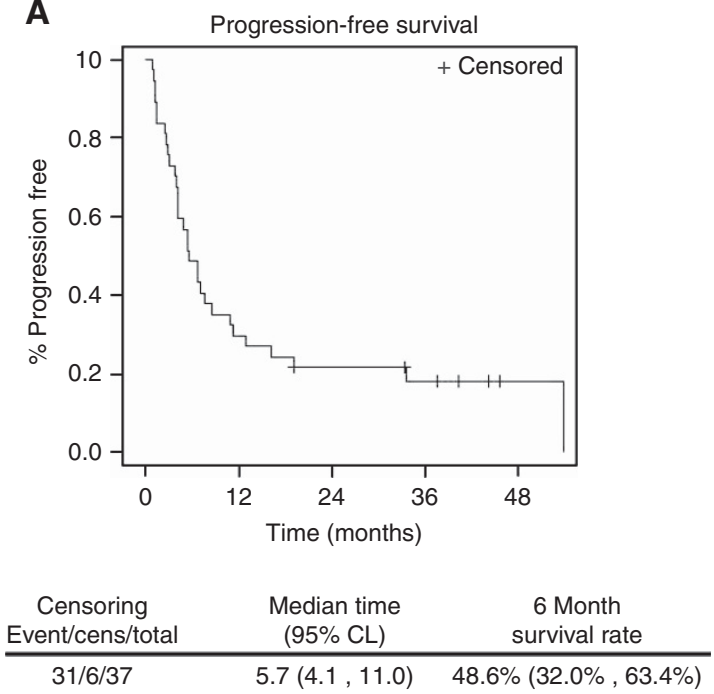

C

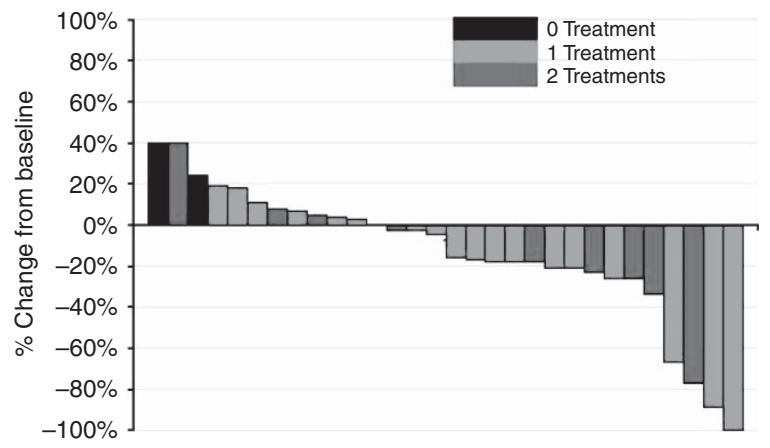

B

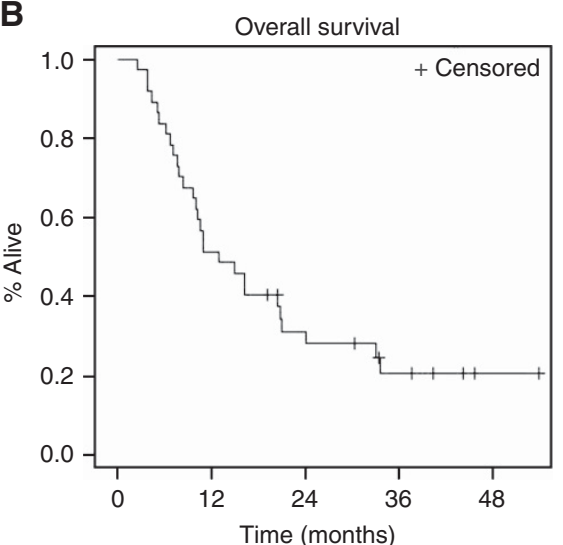

\begin{tabular}{ccc}
$\begin{array}{c}\text { Censoring } \\
\text { Deaths/cens/ } \\
\text { total }\end{array}$ & $\begin{array}{c}\text { Median time } \\
(95 \% \mathrm{CL})\end{array}$ & $\begin{array}{c}6 \text { Month } \\
\text { survival rate }\end{array}$ \\
\hline $28 / 9 / 37$ & $12.9(9.8,20.7)$ & $83.8 \%(67.4 \%, 92.4 \%)$
\end{tabular}

D

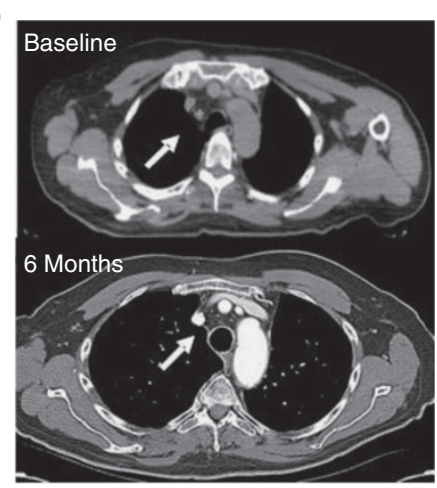

Figure 2. Clinical benefit of vorinostat and bevacizumab in ccRCC patients. (A) Progression-free survival, (B) overall survival, (C) best response to treatment, and (D) representative picture of an objective response (CR).

temsirolimus have shown some evidence of clinical benefit following TKIs, although this was associated with toxicity (Harshman et al, 2013). TRC 105, an anti-endoglin antibody with the combination of bevacizumab produced clinical activity in several patients by reducing tumour volume. Two patients partial response by RECIST, and six patients remained with stable disease without significant toxicities in an anti-VEGF refractory population (Gordon et al, 2014). The recent approval of two additional TKIs, cabozantinib and lenvatinib (in combination with everolimus), in previously treated RCC patients with TKIs confirms the hypothesis that targeting alternative kinases to VEGFR is beneficial (Choueiri et al, 2015; Motzer et al, 2015). Based on our results, we believe that patients presenting progression after first-line TKI may get benefit by rational combination strategies with continuous VEGF blockade and sequential therapies with HDAC inhibitors.

The toxicity profile of the combination of vorinostat and bevacizumab appears to be acceptable. In previous phase I and phase II clinical trials testing vorinostat monotherapy, the recommended doses for continuous oral administration were $400 \mathrm{mg}$ daily and $200 \mathrm{mg}$ twice a day. The DLTs were nonhaematologic (anorexia, dehydration, diarrhoea, and fatigue) and the most common haematologic adverse events were anaemia and thrombocytopenia, rapidly reversible following drug interruption. In our study, we observed similar vorinostat blood levels as reported with single agent (data not shown) and there were no overt overlapping toxicities between the two drugs. The most common side effect was fatigue but no DLTs were observed. Historically, the $400 \mathrm{mg}$ four times a day dosing has been reported to be better tolerated than $200 \mathrm{mg}$ twice a day in terms of fatigue in other combination strategies and further development of vorinostat in combination with bevacizumab would benefit from single daily dosing.

Our correlative studies suggest that modulation of chemokines may be associated with response to treatments targeting the HIF/ VEGF axis. Lack of increase in FGF, OPN, and IL-8 levels in a small subset of patients who achieved durable objective responses as compared with patients who did not respond to treatment confirms the role of alternative pathways in the potential mechanism of resistance to anti-VEGF therapies. Based on our immunohistochemistry studies, in a subset of patients, HIF- $1 \alpha$ and $-2 \alpha$ status in the primary tumours was not associated with response to anti-VEGF treatment. We observed a significant reduction in the platelet-derived VEGF but not in the plasma-derived VEGF, suggesting that quantitative analysis of this growth factor, and perhaps of other chemokines, should be performed in either platelet-enriched or serum samples rather than plasma samples (Verheul et al, 2007). However, the decrease in VEGF levels did not correlate with response. Interestingly, in our analysis patients with objective responses had low levels of platelet-derived VEGF at baseline. Large prospective studies with improved detection kits for VEGF will be critical to further elucidate the predictive role of chemokine levels in response and resistance to VEGF inhibitors. In addition, platelet-derived factors may be relevant in the search of new surrogate markers.

As shown also in other solid tumour types, histone modifier genes may have a role in ccRCC tumourigenesis (Dalgliesh et al, 2010). Recurrent mutations in histone methyltransferases and demethylases suggest that epigenetic changes driven by specific 
A

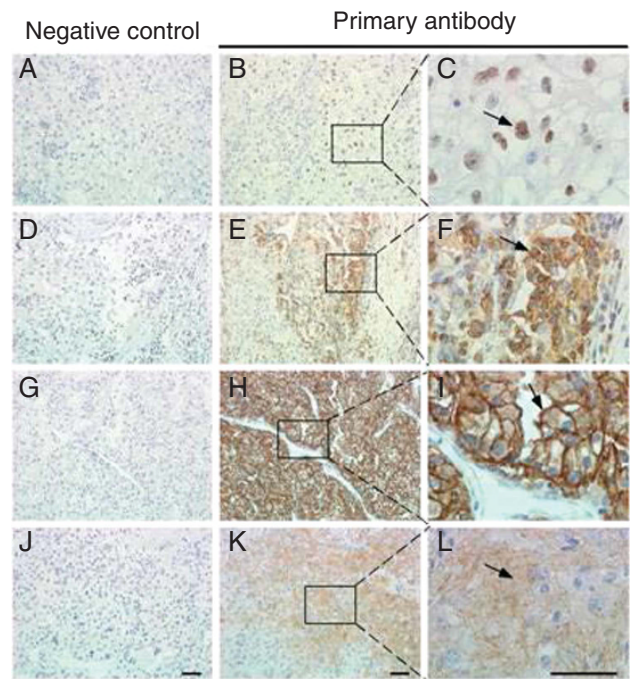

B

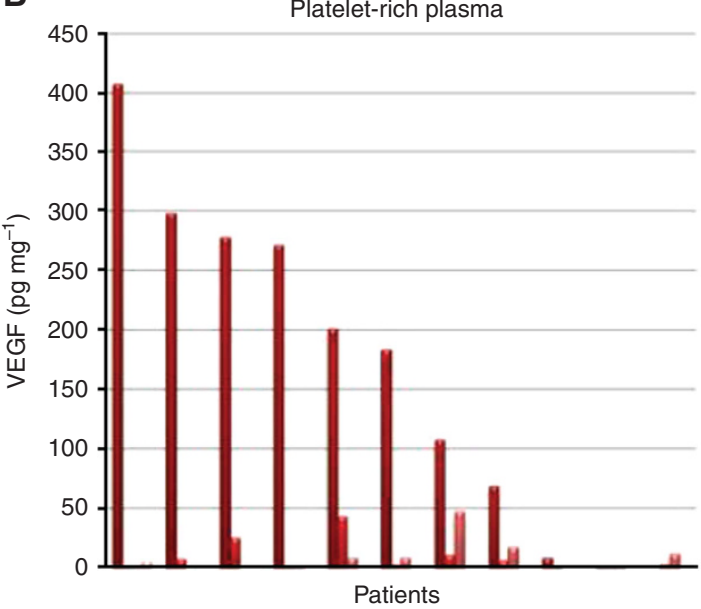

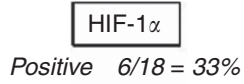

\begin{tabular}{r|} 
HIF-2 $\alpha$ \\
Positive $12 / 18$
\end{tabular}$=67 \%$
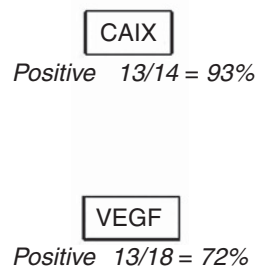

C

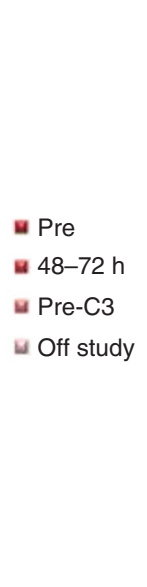

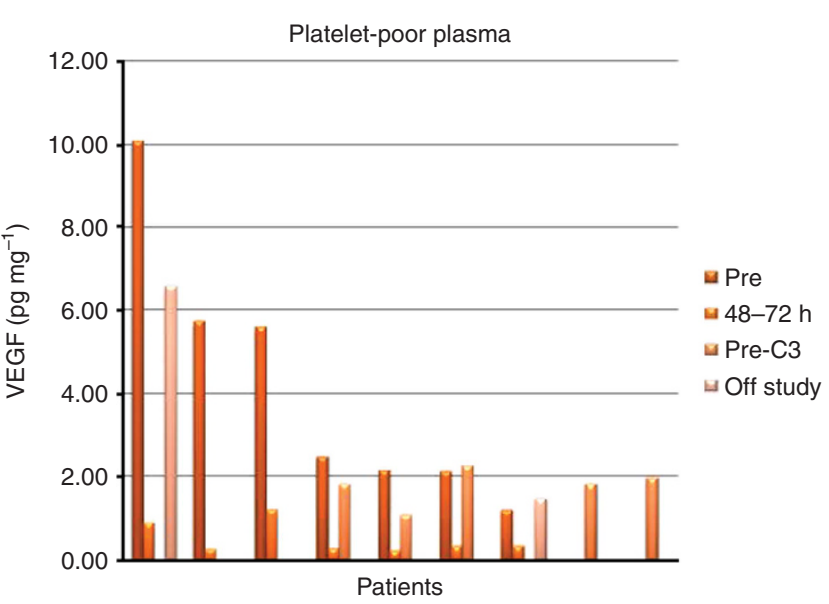

Figure 3. Correlative studies. (A) Representative pictures of immunohistochemistry for VEGF, HIF-1 $\alpha$, HIF-2 $\alpha$, and CAIX in archived tissues from nephrectomies with relative \% expression are reported. (B) Representative serum and (C) plasma levels of VEGF levels at different time points are shown in the subset of patients where complete blood samples were available.

genetic alterations may represent new targets for therapeutic intervention in ccRCC. Specific histone modifier genes such as SETD2 and PBRM1 are most commonly altered in ccRCC and associated with poor prognosis (Hakimi et al, 2013). Data on the functional activity of the enzymes regulated by these genes remain to be elucidated. These observations suggest that ccRCC represents a suitable target for epigenetic therapies. In particular, reports have also shown that HDAC expression is altered in kidney cancer (Ramakrishnan et al, 2013, 2016). However, HDAC expression has not been correlated with response to selective/pan inhibitors. Despite the encouraging preclinical data, the clinical benefit of pan-HDAC inhibitors as single agents has been disappointing in the treatment of solid tumours, including ccRCC. A phase II study with panobinostat did not show meaningful clinical responses in 20 patients with metastatic ccRCC. All patients either progressed or stopped treatment before the 16-week reevaluation (Hainsworth et al, 2011). These results confirm that an effective development of epigenetic agents in solid tumours should not involve single-agent administration, but rather rational combination strategies by taking advantage of transcriptional and post-translational modifications induced by chromatin remodelling compounds.

The role of microRNAs in cancer biology represents an opportunity for developing novel biomarkers both as prognosticators and predictors. The epigenetic regulation of these non- coding RNAs also represents a promising target for therapeutic interventions. Several microRNAs have been identified in ccRCC (Khella et al, 2013), and a miRNA-target interaction network has been proposed (Butz et al, 2015). A recent report has also suggested a potential predictor role of $m i R-221 / 222$ in ccRCC patients receiving sunitinib (Khella et al, 2015). In our analysis, despite the small sample size, modulation of specific circulating microRNAs was associated with tumour response. Interestingly, among the deregulated microRNAs, miR-605 was upregulated in the Responders at baseline and was significantly downregulated following treatment. This microRNA has been involved in microvesicle trafficking and its modulation may suggest that release of specific growth factors/chemokines is associated with response to treatment. As microRNAs are epigenetically regulated in several tumour types, additional studies are necessary to determine the role of vorinostat and epigenetic agents in the observed modulation. Modulation of microRNAs including $m i R-20 a, 142-3 p, 154$, $99 a, 199 a$, let7b, 365, and 451 by different HDAC inhibitors has been reported (Ali et al, 2015). Similar microRNAs were found altered with the treatment of vorinostat in our ccRCC patients (Figure 4B). Furthermore, vorinostat has been reported to specifically alter miRNA 20a, 142-3p, 199a, let7b, and 365 in ovarian cancer cells (Balch et al, 2012), miRNA 142-3p and 99a in renal cancer cells (Schiffgen et al, 2013), miR-let7b in ras- 
A
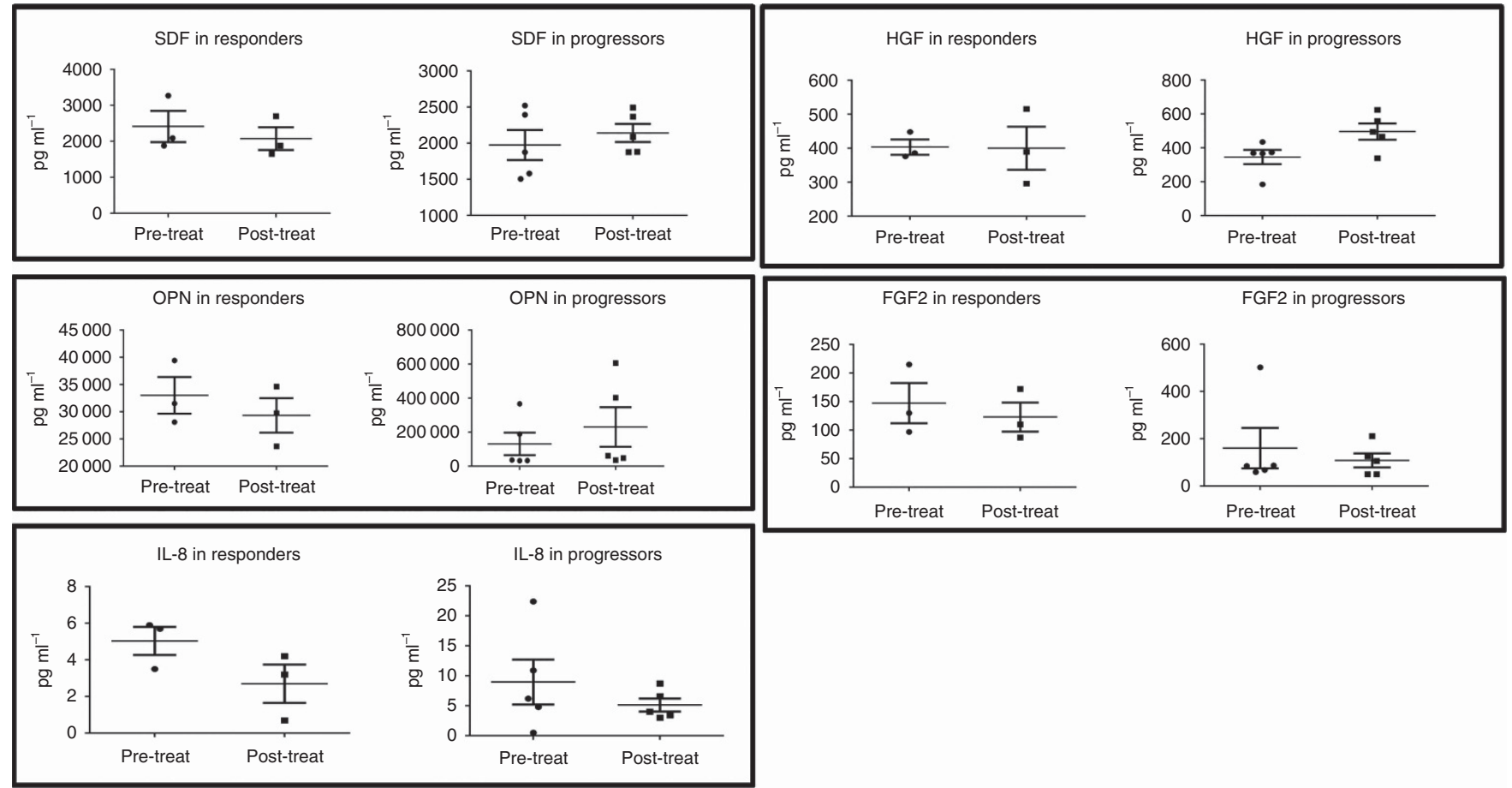

B
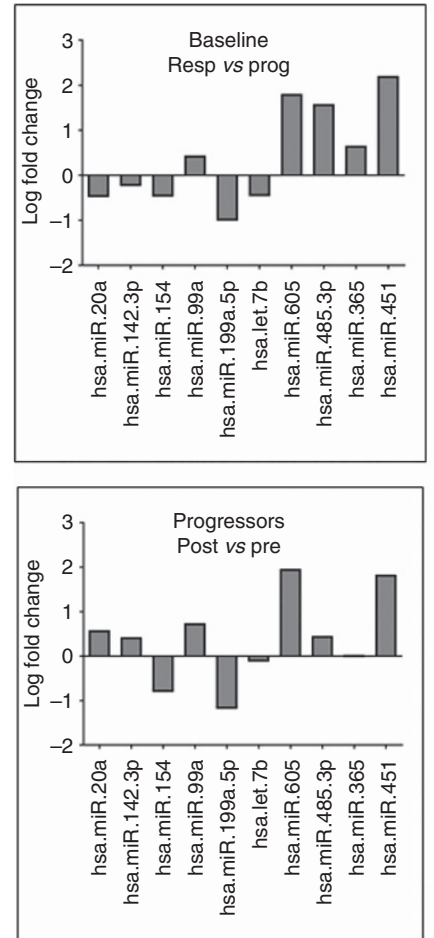

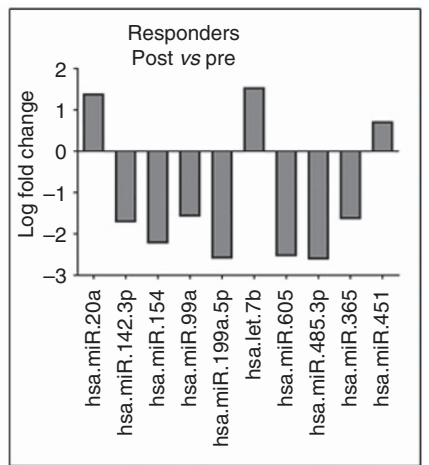

C

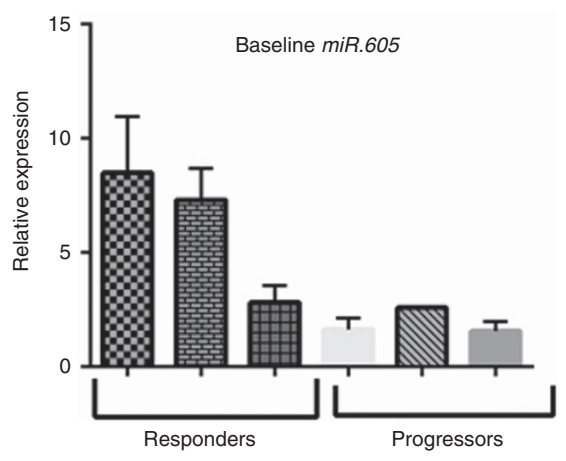

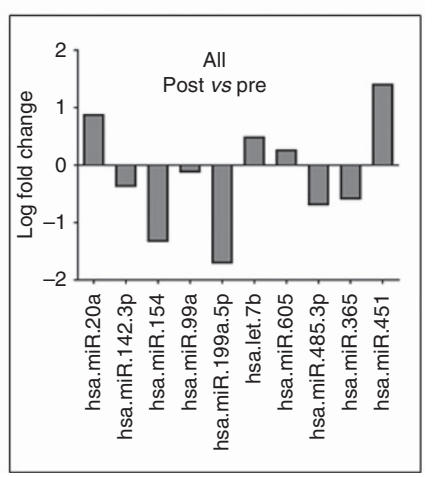

Figure 4. Chemokines and miRNA. (A) Differential modulation of serum chemokines in Responders vs Progressors. (B) differential modulation of serum miRNAs in Responders vs Progressors. (C) Baseline expression of circulating miR-605 in serum Responders vs Progressors. Bands represent individual patients.

transformed thyroid cells (Borbone et al, 2013) and lung cancer cells (Lee et al, 2009), and $m i R-20 a$ in acute myeloid leukaemia cells (Lepore et al, 2013) and liver cancer cells (Yang et al, 2015). Our findings on circulating microRNA and their modulation by vorinostat in ccRCC patients serum is quite interesting. In particular, we found that miR-605 is elevated at baseline in the Responders and is downregulated with treatment in Responders as compared with Progressors, suggesting its tumour-suppressor role (Figures 4A and C). Interestingly, miR-605 has been reported to cross-talk with p53 (Xiao et al, 2011), and phase I trial with vorinostat plus pazopanib has reported clinical benfit in patients with mutated p53 colon carcinoma and sarcoma (Fu et al, 2015). Further testing is warranted to identify the molecular targets of these microRNAs in ccRCC to better understand the mechanism(s) of resistance/sensitivity to antiVEGF therapies. 
In summary, our results highlight that the combination of vorinostat and bevacizumab is safe, and further clinical investigation would be warranted to clarify whether this combination has greater efficacy $v s$ bevacizumab alone. We recognise that our study has several limitations including the small sample size and the single-arm design. However, we are also encouraged from the results of a recently reported phase I study with the HDAC inhibitor abexinostat in combination with the VEGF TKI pazopanib showing $18 \%$ response rate in previously treated RCC patients (Aggarwal et al, 2016). Further analysis of patients responding to epigenetic therapies in the context of VEGF inhibition will identify the subset of ccRCC patients who may benefit from this combination therapeutic strategy.

\section{ACKNOWLEDGEMENTS}

We acknowledge the Genomics Shared Resources (GSR) and Bioinformatics Shared Resources (BSR) at Roswell Park Cancer Institute for the analysis of microRNA in the clinical samples. This study was, in part, supported by NCI U01-CA-70095 (to MAC), NCI UO1-CA-062491 (to GL), NCI-1R21CA121590 (to RP), and NCI P30CA16056 (to RP).

\section{CONFLICT OF INTEREST}

The authors declare no conflict of interest.

\section{REFERENCES}

Aggarwal RR, Thomas S, Grabowsky JA, Harb A, Leng J, Reinert A, Mastroserio I, Truong TG, Munster PN (2016) Abexinostat (ABX) as a means to reverse pazopanib (PAZ) resistance: a phase 1 study in advanced solid tumor malignancies. J Clin Oncol 34(Suppl): abstract 2519.

Ali SR, Humphreys KJ, McKinnon RA, Michael MZ (2015) Impact of histone deacetylase inhibitors on microRNA expression and cancer therapy: a review. Drug Dev Res 76: 296-317.

Balch C, Naegeli K, Nam S, Ballard B, Hyslop A, Melki C, Reilly E, Hur MW, Nephew KP (2012) A unique histone deacetylase inhibitor alters microRNA expression and signal transduction in chemoresistant ovarian cancer cells. Cancer Biol Ther 13(8): 681-693.

Butz H, Szabó PM, Khella HW, Nofech-Mozes R, Patocs A, Yousef GM (2015) miRNA-target network reveals miR-124as a key miRNA contributing to clear cell renal cell carcinoma aggressive behaviour by targeting CAV1 and FLOT1. Oncotarget 6(14): 12543-12557.

Borbone E, De Rosa M, Siciliano D, Altucci L, Croce CM, Fusco A (2013) Upregulation of miR-146b and down-regulation of miR-200b contribute to the cytotoxic effect of histone deacetylase inhibitors on ras-transformed thyroid cells. J Clin Endocrinol Metab 98(6): E1031-E1040.

Chintala S, Najrana T, Toth K, Cao S, Durrani FA, Pili R, Rustum YM (2012) Prolyl hydroxylase 2 dependent and Von-Hippel-Lindau independent degradation of hypoxia-inducible factor 1 and 2 alpha by selenium in clear cell renal cell carcinoma leads to tumor growth inhibition. BMC Cancer 12: 293 .

Chintala S, Toth K, Cao S, Durrani FA, Vaughan MM, Jensen RL, Rustum YM (2010) Se-methylselenocysteine sensitizes hypoxic tumor cells to irinotecan by targeting hypoxia-inducible factor 1alpha. Cancer Chemother Pharmacol 66(5): 899-911.

Choueiri TK, Escudier B, Powles T, Mainwaring PN, Rini BI, Donskov F, Hammers H, Hutson TE, Lee JL, Peltola K, Roth BJ, Bjarnason GA, Géczi L, Keam B, Maroto P, Heng DY, Schmidinger M, Kantoff PW, Borgman-Hagey A, Hessel C, Scheffold C, Schwab GM, Tannir NM, Motzer RJ, METEOR Investigators (2015) Cabozantinib versus everolimus in advanced renal-cell carcinoma. N Engl J Med 373(19): 1814-1823.

Dalgliesh GL, Furge K, Greenman C, Chen L, Bignell G, Butler A, Davies H, Edkins S, Hardy C, Latimer C, Teague J, Andrews J, Barthorpe S, Beare D, Buck G, Campbell PJ, Forbes S, Jia M, Jones D, Knott H, Kok CY, Lau KW, Leroy C, Lin ML, McBride DJ, Maddison M, Maguire S,
McLay K, Menzies A, Mironenko T, Mulderrig L, Mudie L, O’Meara S, Pleasance E, Rajasingham A, Shepherd R, Smith R, Stebbings L,

Stephens P, Tang G, Tarpey PS, Turrell K, Dykema KJ, Khoo SK, Petillo D, Wondergem B, Anema J, Kahnoski RJ, Teh BT, Stratton MR, Futreal PA (2010) Systematic sequencing of renal carcinoma reveals inactivation of histone modifying genes. Nature 463(7279): 360-363.

Ellis L, Hammers H, Pili R (2009) Targeting tumor angiogenesis with histone deacetylase inhibitors. Cancer Lett 280(2): 145-153.

Fu S, Hou MM, Naing A, Janku F, Hess K, Zinner R, Subbiah V, Hong D, Wheler J, Piha-Paul S, Tsimberidou A, Karp D, Araujo D, Kee B, Hwu P, Wolff R, Kurzrock R, Meric-Bernstam F (2015) Phase I study of pazopanib and vorinostat: a therapeutic approach for inhibiting mutant p53-mediated angiogenesis and facilitating mutant p53 degradation. Ann Oncol 26(5): 1012-1018.

Gordon MS, Robert F, Matei D, Mendelson DS, Goldman JW, Chiorean EG, Strother RM, Seon BK, Figg WD, Peer CJ, Alvarez D, Adams BJ, Theuer CP, Rosen LS (2014) An open-label phase Ib dose-escalation study of TRC105 (anti-endoglin antibody) with bevacizumab in patients with advanced cancer. Clin Cancer Res 20(23): 5918-5926.

Hainsworth JD, Infante JR, Spigel DR, Arrowsmith ER, Boccia RV, Burris HA (2011) A phase II trial of panobinostat, a histone deacetylase inhibitor, in the treatment of patients with refractory metastatic renal cell carcinoma. Cancer Invest 29(7): 451-455.

Hakimi AA, Ostrovnaya I, Reva B, Schultz N, Chen YB, Gonen M, Liu H, Takeda S, Voss MH, Tickoo SK, Reuter VE, Russo P, Cheng EH, Sander C, Motzer RJ, Hsieh JJ, cc RCCCGARNi (2013) Adverse outcomes in clear cell renal cell carcinoma with mutations of 3p21 epigenetic regulators BAP1 and SETD2: a report by MSKCC and the KIRC TCGA research network. Clin Cancer Res 19(12): 3259-3267.

Hammers HJ, Verheul HM, Salumbides B, Sharma R, Rudek M, Jaspers J, Shah P, Ellis L, Shen L, Paesante S, Dykema K, Furge K, Teh BT, Netto G, Pili R (2010) Reversible epithelial to mesenchymal transition and acquired resistance to sunitinib in patients with renal cell carcinoma: evidence from a xenograft study. Mol Cancer Ther 9(6): 1525-1535.

Harshman LC, Barbeau S, McMillian A, Srinivas S (2013) A phase II study of bevacizumab and everolimus as treatment for refractory metastatic renal cell carcinoma. Clin Genitourin Cancer 11(2): 100-106.

Heng DY, Xie W, Regan MM, Harshman LC, Bjarnason GA, Vaishampayan UN, Mackenzie M, Wood L, Donskov F, Tan MH, Rha SY, Agarwal N, Kollmannsberger C, Rini BI, Choueiri TK (2013) External validation and comparison with other models of the International Metastatic Renal-Cell Carcinoma Database Consortium prognostic model: a population-based study. Lancet Oncol 14(2): 141-148.

Huang D, Ding Y, Zhou M, Rini BI, Petillo D, Qian CN, Kahnoski R, Futreal PA, Furge KA, Teh BT (2010) Interleukin-8 mediates resistance to antiangiogenic agent sunitinib in renal cell carcinoma. Cancer Res 70(3): 1063-1071.

Jeong W, Rapisarda A, Park SR, Kinders RJ, Chen A, Melillo G, Turkbey B, Steinberg SM, Choyke P, Doroshow JH, Kummar S (2014) Pilot trial of EZN-2968, an antisense oligonucleotide inhibitor of hypoxia-inducible factor-1 alpha (HIF-1alpha), in patients with refractory solid tumors. Cancer Chemother Pharmacol 73(2): 343-348.

Kaelin WG Jr (2004) The von Hippel-Lindau tumor suppressor gene and kidney cancer. Clin Cancer Res 10(18, Part 2): 6290S-6295SS.

Khella HW, Bakhet M, Allo G, Jewett MA, Girgis AH, Latif A, Girgis H, Von Both I, Bjarnason GA, Yousef GM (2013) miR-192, miR-194 and miR-215: a convergent microRNA network suppressing tumor progression in renal cell carcinoma. Carcinogenesis 34(10): 2231-2239.

Khella HW, Butz H, Ding Q, Rotondo F, Evans KR, Kupchak P, Dharsee M, Latif A, Pasic MD, Lianidou E, Bjarnason GA, Yousef GM (2015) miR-221/222 are involved in response to sunitinib treatment in metastatic renal cell carcinoma. Mol Ther 23(11): 1748-1758.

Kummar S, Raffeld M, Juwara L, Horneffer Y, Strassberger A, Allen D, Steinberg SM, Rapisarda A, Spencer SD, Figg WD, Chen X, Turkbey IB, Choyke P, Murgo AJ, Doroshow JH, Melillo G (2011) Multihistology, target-driven pilot trial of oral topotecan as an inhibitor of hypoxia-inducible factor-1alpha in advanced solid tumors. Clin Cancer Res 17(15): 5123-5131.

Lee EM, Shin S, Cha HJ, Yoon Y, Bae S, Jung JH, Lee SM, Lee SJ, Park IC, Jin YW, An S (2009) Suberoylanilide hydroxamic acid (SAHA) changes microRNA expression profiles in A549 human non-small cell lung cancer cells. Int J Mol Med 24(1): 45-50.

Lepore I, Dell'Aversana C, Pilyugin M, Conte M, Nebbioso A, De Bellis F, Tambaro FP, Izzo T, Garcia-Manero G, Ferrara F, Irminger-Finger I, Altucci L 
(2013) HDAC inhibitors repress BARD1 isoform expression in acute myeloid leukemia cells via activation of miR-19a and/or b. PLoS One 8(12): e83018.

Marks PA (2007) Discovery and development of SAHA as an anticancer agent. Oncogene 26(9): 1351-1356.

Mittal K, Rini B (2013) Kidney cancer in 2012: new frontiers in kidney cancer research. Nat Rev Urol 10(2): 70-72.

Motzer RJ, Hutson TE, Glen H, Michaelson MD, Molina A, Eisen T, Jassem J, Zolnierek J, Maroto JP, Mellado B, Melichar B, Tomasek J, Kremer A, Kim HJ, Wood K, Dutcus C, Larkin J (2015) Lenvatinib, everolimus, and the combination in patients with metastatic renal cell carcinoma: a randomised, phase 2, open-label, multicentre trial. Lancet Oncol 16(15): 1473-1482.

Olsen EA, Kim YH, Kuzel TM, Pacheco TR, Foss FM, Parker S, Frankel SR, Chen C, Ricker JL, Arduino JM, Duvic M (2007) Phase IIb multicenter trial of vorinostat in patients with persistent, progressive, or treatment refractory cutaneous T-cell lymphoma. J Clin Oncol 25(21): 3109-3115.

Qian DZ, Kachhap SK, Collis SJ, Verheul HM, Carducci MA, Atadja P, Pili R (2006a) Class II histone deacetylases are associated with VHL-independent regulation of hypoxia-inducible factor 1 alpha. Cancer Res 66(17): 8814-8821.

Qian DZ, Kato Y, Shabbeer S, Wei Y, Verheul HM, Salumbides B, Sanni T, Atadja P, Pili R (2006b) Targeting tumor angiogenesis with histone deacetylase inhibitors: the hydroxamic acid derivative LBH589. Clin Cancer Res 12(2): 634-642.

Qian DZ, Wang X, Kachhap SK, Kato Y, Wei Y, Zhang L, Atadja P, Pili R (2004) The histone deacetylase inhibitor NVP-LAQ824 inhibits angiogenesis and has a greater antitumor effect in combination with the vascular endothelial growth factor receptor tyrosine kinase inhibitor PTK787/ZK222584. Cancer Res 64(18): 6626-6634.

Ramakrishnan S, Ellis L, Pili R (2013) Histone modifications: implications in renal cell carcinoma. Epigenomics 5(4): 453-462.

Ramakrishnan S, Ku S, Ciamporcero E, Miles KM, Attwood K, Chintala S, Shen L, Ellis L, Sotomayor P, Swetzig W, Huang R, Conroy D, Orillion A, Das G, Pili R (2016) HDAC 1 and 6 modulate cell invasion and migration in clear cell renal cell carcinoma. BMC Cancer 16: 617-632.

Rapisarda A, Hollingshead M, Uranchimeg B, Bonomi CA, Borgel SD, Carter JP, Gehrs B, Raffeld M, Kinders RJ, Parchment R, Anver MR, Shoemaker RH, Melillo G (2009) Increased antitumor activity of bevacizumab in combination with hypoxia inducible factor-1 inhibition. Mol Cancer Ther 8(7): 1867-1877.

Redova M, Poprach A, Nekvindova J, Iliev R, Radova L, Lakomy R, Svoboda M, Vyzula R, Slaby O (2012) Circulating miR-378 and miR-451 in serum are potential biomarkers for renal cell carcinoma. J Transl Med 10: 55.

Rini BI (2011) Targeted therapy for patients with renal-cell carcinoma. Lancet Oncol 12(12): 1085-1087.
Rini BI, Escudier B, Tomczak P, Kaprin A, Szczylik C, Hutson TE, Michaelson MD, Gorbunova VA, Gore ME, Rusakov IG, Negrier S, Ou YC, Castellano D, Lim HY, Uemura H, Tarazi J, Cella D, Chen C, Rosbrook B, Kim S, Motzer RJ (2011) Comparative effectiveness of axitinib versus sorafenib in advanced renal cell carcinoma (AXIS): a randomised phase 3 trial. Lancet 378(9807): 1931-1939.

Rini BI, Halabi S, Rosenberg JE, Stadler WM, Vaena DA, Ou SS, Archer L, Atkins JN, Picus J, Czaykowski P, Dutcher J, Small EJ (2008) Bevacizumab plus interferon alfa compared with interferon alfa monotherapy in patients with metastatic renal cell carcinoma: CALGB 90206. J Clin Oncol 26(33): 5422-5428.

Schiffgen M, Schmidt DH, von Rucker A, Muller SC, Ellinger J (2013) Epigenetic regulation of microRNA expression in renal cell carcinoma. Biochem Biophys Res Commun 436(1): 79-84.

Shen C, Kaelin WG Jr (2013) The VHL/HIF axis in clear cell renal carcinoma. Semin Cancer Biol 23(1): 18-25.

Therasse P, Arbuck SG, Eisenhauer EA, Wanders J, Kaplan RS, Rubinstein L, Verweij J, Van Glabbeke M, van Oosterom AT, Christian MC, Gwyther SG (2000) New guidelines to evaluate the response to treatment in solid tumors. European Organization for Research and Treatment of Cancer, National Cancer Institute of the United States, National Cancer Institute of Canada. J Natl Cancer Inst 92(3): 205-216.

Turnbull JD, Cobert J, Jaffe T, Harrison MR, George DJ, Armstrong AJ (2013) Activity of single-agent bevacizumab in patients with metastatic renal cell carcinoma previously treated with vascular endothelial growth factor tyrosine kinase inhibitors. Clin Genitourin Cancer 11(1): 45-50.

Verheul HM, Lolkema MP, Qian DZ, Hilkes YH, Liapi E, Akkerman JW, Pili R, Voest EE (2007) Platelets take up the monoclonal antibody bevacizumab. Clin Cancer Res 13(18, Part 1): 5341-5347.

Yang H, Lan P, Hou Z, Guan Y, Zhang J, Xu W, Tian Z, Zhang C (2015) Histone deacetylase inhibitor SAHA epigenetically regulates miR-17-92 cluster and MCM7 to upregulate MICA expression in hepatoma. $\mathrm{Br} \mathrm{J}$ Cancer 112(1): 112-121.

Xiao J, Lin H, Luo X, Luo X, Wang Z (2011) miR-605 joins p53 network to form a p53:miR-605:Mdm2 positive feedback loop in response to stress. EMBO J 30(3): 524-532.

This work is published under the standard license to publish agreement. After 12 months the work will become freely available and the license terms will switch to a Creative Commons AttributionNonCommercial-Share Alike 4.0 Unported License. 